\title{
Giant retinal tears: clinical features and outcomes of vitreoretinal surgery at a university teaching hospital (20II-2017)
}

This article was published in the following Dove Press journal:

Clinical Ophthalmology

\author{
Marianeli Rodriguez \\ James Lin \\ Justin $\mathrm{H}$ Townsend \\ William E Smiddy \\ Thomas A Albini \\ Audina M Berrocal \\ Jayanth Sridhar \\ Harry W Flynn Jr
}

Department of Ophthalmology, Bascom Palmer Eye Institute, Miller School of Medicine, University of

Miami, Miami, FL, USA
Correspondence: James Lin

Department of Ophthalmology, Bascom Palmer Eye Institute, University of Miami, 900 NW 17th St, Miami, FL 33।36, USA Email jxII834@med.miami.edu
Purpose: The purpose of this study was to report clinical features and outcomes in patients with giant retinal tears (GRTs) undergoing vitreoretinal surgery and to compare data from this contemporary series to a previous study from the same institution.

Materials and methods: A retrospective, interventional, consecutive case series was conducted for all patients diagnosed with GRTs who underwent vitreoretinal surgery between January 2011 and August 2017. Intraoperative data including the use of scleral buckling, perfluorocarbon liquid, and intraocular tamponade were collected and compared according to GRT size. These parameters, along with postoperative anatomic success and best-corrected visual acuity (BCVA), were compared with the previous series.

Results: The study included 80 eyes of 79 patients with a presentation of retinal detachment with a GRT. Management approach for repair of GRT-associated retinal detachments included scleral buckle (SB) alone (three eyes, 4\%), pars plana vitrectomy (PPV) (16 eyes, 20\%), and combined SB/PPV (61 eyes, 76\%). Perfluorocarbon liquids were used in 60/77 eyes $(78 \%)$ undergoing PPV, and silicone oil was used in 54/77 eyes (70\%). Single surgery success rate was in 69/80 eyes (86\%). Eyes managed with SB (including SB alone and SB/PPV) or PPV without SB had similar rates of recurrent retinal detachment ( $16 \%$ vs $6 \% ; P=0.33$ ). Anatomic success was achieved in 76/80 eyes (95\%) with one or more surgical procedures, and 54/80 eyes (68\%) achieved postoperative BCVA of $\geq 20 / 400$.

Conclusions: In the current series, repairs of retinal detachment due to GRTs were most commonly managed with combined PPV/SB and perfluorocarbon liquid, resulting in reasonably generally favorable anatomic and visual outcomes.

Keywords: giant retinal tears, perfluorocarbon liquid, retinal detachment, vitrectomy

\section{Introduction}

A giant retinal tear (GRT) is defined as a full-thickness break in the retina equal to or larger than 3 clock hours associated with vitreous detachment. ${ }^{1}$ Risk factors for developing a GRT include trauma, high myopia, Marfan syndrome, Stickler's syndrome or other hereditary vitreoretinopathies, and extensive lattice degeneration. ${ }^{2,3}$ Additional etiologies for GRT include iatrogenic and idiopathic causes.

The frequent rolled posterior edge of the retinal flap renders repair of retinal detachment (RD) due to GRTs technically challenging. Attempts to improve treatment through the 1970s and 1980s involved prone positioning for fluid-gas exchange, rotating head movements ("steamrolling") to unfold the tear, and manipulation of the retinal flap using intraocular balloons, retinal microincarceration, tissue adhesives, sodium hyaluronate, and retinal tacks, screws, and sutures. ${ }^{4,5}$ The advent of perfluorocarbon 
liquids changed the way that these cases were approached and allowed for higher surgical success rates as it made the surgical technique easier. ${ }^{6}$ Currently, there is still debate about whether adjunctive procedures such as scleral buckling, lensectomy, or silicone oil injection are recommended.

Thus, the optimal surgical approach for these challenging cases remains controversial. The current study represents an update to a previously reported noncomparative case series of patients with GRT-associated RDs undergoing primary management at a university referral center. ${ }^{7}$

\section{Materials and methods}

In accordance with the guidelines from the Declaration of Helsinki, this study was approved by the Institutional Review Board at the University of Miami, Miller School of Medicine, as a retrospective noncomparative case series of patients undergoing primary RD repair for GRT at the Bascom Palmer Eye Institute between January 2011 and August 2017. The Institutional Review Board at the University of Miami did not require patient consent for retrospective review of medical records, and all patient data were deidentified upon review. Patients with a history of retinopathy of prematurity or retinal tear of less than 3 clock hours were excluded from this study.

Patients were identified using the ICD-10 codes for GRTs (H33.031, H33.032, H33.033, H33.039), and their charts were reviewed to verify coding information. A total of 427 patients were initially reviewed, yielding 80 eyes of 79 patients that fulfilled the abovementioned inclusion and exclusion criteria.

Data collected included demographic information, recorded etiologies, and surgical techniques. Outcome variables that were studied included best-corrected visual acuity (BCVA), occurrence of single operation retinal reattachment, and occurrence of reoperation. Data were collected postoperatively at 1 week, 1 month, 3 months, 6 months, 1 year, and last follow-up date. The surgical technique was at the discretion of the individual surgeon since there was no defined surgical protocol for this study. The data on proliferative vitreoretinopathy (PVR) were not included in this study as there were inconsistencies in the medical records and lack of standardization in its classification among the surgeons. Current data were compared with data from a previously published article from the same institution from 2005 to $2010 .^{7}$ Surgical variables were analyzed using the chi-squared test and Student's $t$-test. All statistical analyses were performed using SPSS version 24.0 (IBM Corporation, Armonk, NY, USA).

\section{Results}

This study comprises 80 eyes of 79 patients who had an initial presentation of GRT associated with RD. The study included $62(78 \%)$ male subjects. The mean age at initial presentation was $48.1 \pm 16$ years, ranging from 4 to 71 years. The mean follow-up interval was $10.3 \pm 9$ months. Right eyes were involved in 42/80 eyes (53\%). Principal associations for the development of GRTs included prior history of blunt trauma ( 23 eyes, $18 \%$ ), high myopia $\geq 6$ diopters ( 33 eyes, $26 \%$ ), lattice degeneration ( 14 eyes, $11 \%$ ), and prior RD in the fellow eye (12 eyes, 10\%). Other less common associations of GRTs included Marfan syndrome (two eyes, 2\%) and Stickler's syndrome (one eye, 1\%).

The size of the GRT was $<180^{\circ}$ in $60 / 80$ eyes $(75 \%)$ (Table 1). The majority (68\% of eyes) of the GRTs were superior and temporal. The associated RD was macular involving in $65 \%$. The majority of eyes $(76 \%)$ were initially phakic, while $21 \%$ were pseudophakic, and $2.5 \%$ were aphakic.

Primary scleral buckle (SB) was performed in 3/80 eyes (4\%), with two patients receiving the \#41 band and one patient receiving the \#240 band (Table 2). These eyes were buckled because they were inferior GRTs without rolled edges, and 2 of the 3 eyes had shallow detachments. The majority of eyes $(61 / 80,76 \%)$ were treated with a combined pars plana vitrectomy (PPV) and SB procedure, utilizing a combination of the \#41, \#42, and \#240 bands. All PPVs were performed with either 23 or 25 gauge instrumentation. PPV alone was performed in 16 eyes (20\%). In cases of PPV, endolaser was applied in a confluent fashion for one or two rows posterior to the GRT. In the three cases with SB only, cryopexy was used. Lensectomy was performed in $9 / 61$ phakic eyes (15\%). Perfluorocarbon liquid was used

Table I Initial anatomic characteristics of patients undergoing surgery for GRT-related retinal detachment

\begin{tabular}{|c|l|}
\hline & N (\%) \\
\hline Extent of GRT & \\
\hline$<180^{\circ}$ & $60(75)$ \\
\hline$\geq 180^{\circ}$ & $20(25)$ \\
\hline Average size of GRT, clock hours (SD) & $4.5(1.8)$ \\
\hline Macula status, $\mathrm{n}(\%)$ & \\
\hline On & $28(35)$ \\
\hline Off & $52(65)$ \\
\hline Lens status, n (\%) & \\
\hline Phakic & $6 \mathrm{I}(76)$ \\
\hline Pseudophakic & $17(2 \mathrm{I})$ \\
\hline Aphakic & $2(2.5)$ \\
\hline
\end{tabular}

Abbreviation: GRT, giant retinal tear. 
Table 2 Intraoperative data for patients with giant retinal tearrelated retinal detachments

\begin{tabular}{|l|l|}
\hline Intraoperative parameters & $\mathbf{N}(\%)$ \\
\hline Primary SB & $3(3.8)$ \\
\hline Primary PPV & $\mathrm{I} 6(20)$ \\
\hline Combined PPV/SB & $6 \mathrm{I}(76)$ \\
\hline Intraocular tamponade & \\
\hline I) $\mathrm{SF}_{6}$ & $\mathrm{I}(1.3)$ \\
\hline 2) $\mathrm{C}_{3} \mathrm{~F}_{8}$ & $22(28)$ \\
\hline 3) Silicone oil & $54(68)$ \\
\hline Perfluorocarbon liquid use & $60(78)$ \\
\hline
\end{tabular}

Abbreviations: $\mathrm{C}_{3} \mathrm{~F}_{8}$, perfluoropropane; PPV, pars plana vitrectomy; SB, scleral buckle; $\mathrm{SF}_{6}$, sulfur hexafluoride.

in 60/77 eyes (78\%) undergoing PPV. Among eyes treated with PPV, silicone oil was used in 54/77 eyes (70\%), perfluoropropane $\left(\mathrm{C}_{3} \mathrm{~F}_{8}\right)$ was used in 22/77 eyes $(29 \%)$, and sulfur hexafluoride $\left(\mathrm{SF}_{6}\right)$ was used in $1 / 77$ eyes $(1 \%)$.

SB was more likely to be placed in phakic eyes compared with pseudophakic/aphakic eyes (52/61 eyes, $85 \%$ vs $12 / 19$ eyes, $63 \% ; P<0.036$ ). Recurrent RD occurred in $1 / 3$ eyes $(33 \%)$ that received only a primary SB. However, eyes that received an initial SB (with or without PPV) had the same recurrent $\mathrm{RD}$ rate compared with cases managed without $\mathrm{SB}(10 / 64$ eyes, $16 \%$ vs $1 / 16$ eyes, $6 \% ; P=0.33)$. Eyes associated with trauma had similar rates of recurrent $\mathrm{RD}$ compared with those not associated with trauma $(P=0.55)$. For internal tamponade, there was no difference in rates of primary success between silicone oil (87\%) and $\mathrm{C}_{3} \mathrm{~F}_{8}(91 \%, P=0.6)$, but the one eye treated initially with $\mathrm{SF}_{6}$ developed a recurrent $\mathrm{RD}$.

Perfluorocarbon liquid was used equally (and frequently) in GRTs involving both $<180^{\circ}$ and $\geq 180^{\circ}: 47$ eyes (78\%) vs 16 eyes $(80 \%)$, respectively (Table 3$)$. Silicone oil was more frequently used as tamponade in eyes with GRTs $\geq 180^{\circ}$ compared with $\mathrm{C}_{3} \mathrm{~F}_{8}(14 / 20,70 \%$ vs $6 / 20,30 \% ; P=0.01)$ and also was more commonly used for GRTs $<180^{\circ}$ ( $40 / 60$ eyes, $67 \%$ vs $16 / 60,27 \% ; P<0.001)$. GRTs $\geq 180^{\circ}$ were not less likely to be attached at final follow-up and were not more likely to require further surgery for a recurrent RD compared with GRTs $<180^{\circ}$ (Table 3 ). The percentage with final BCVA $\geq 20 / 400$ was not different in those presenting with GRTs $\geq 180^{\circ}$ compared with GRTs $<180^{\circ}$. Rate of lensectomy was not different between phakic eyes with GRTs $\geq 180^{\circ}$ compared with GRTs $<180^{\circ}$ (Table 3 ).

The retina was reattached at the last recorded follow-up examination in 76/80 eyes (95\%). Recurrent RD after the primary repair occurred in $11 / 80$ eyes $(14 \%)$. The silicone oil had been removed in 24/54 eyes (44\%) with silicone oil tamponade at last follow-up (Figure 1). Of these eyes, $5 / 24$ (21\%) had recurrent detachment, and 1/54 eyes ( $2 \%$ ) required a silicone oil exchange. Retinal redetachment occurred in 4/11 eyes (36\%) after silicone oil was removed, with all redetachments occurring an average of 3 months after initial repair. When comparing with GRT size, 5/14 (36\%) of the GRTs $\geq 180^{\circ}$ had oil removed compared with $18 / 40$ (45\%) of the GRTs $<180^{\circ}(P=0.55)$.

Preoperative visual acuity was $\geq 20 / 400$ in 43 eyes (54\%). At 6 months, only one eye (1\%) had BCVA $\geq 20 / 40$ and 16 eyes $(20 \%)$ had BCVA $\geq 20 / 400$. At 1 year, four eyes ( $5 \%$ ) had BCVA $\geq 20 / 40$ and 21 eyes (26\%) had BCVA $\geq 20 / 400$. At last follow-up examination, 15 eyes (19\%) had BCVA of $\geq 20 / 40$ and 54 eyes (68\%) had $\geq 20 / 400$. Compared with visual acuity at initial presentation, 51 eyes $(64 \%)$ had stable or improvement in BCVA at final follow-up. There was no difference in mean final BCVA between eyes with macula-off vs macula-on RDs $(P=0.27)$. No difference was seen in mean final BCVA between eyes with silicone oil tamponade vs $\mathrm{C}_{3} \mathrm{~F}_{8}(P=0.40)$.

The surgical management and results from the earlier case series of 79 eyes were similar to that of this series in terms of SB use, silicone oil use, final reattachment rate, and visual acuity outcomes (Table 4). ${ }^{7}$ The final reattachment rate in the current series was $95 \%$ compared with $92 \%$ in

Table 3 Perfluorocarbon liquid use, lensectomy, anatomic, and visual outcomes by GRT extent

\begin{tabular}{|c|c|c|c|}
\hline Extent of GRT & $\begin{array}{l}<180^{\circ} \\
\mathrm{N}=60(\%)\end{array}$ & $\begin{array}{l}\geq 180^{\circ} \\
\mathbf{N}=\mathbf{2 0}(\%)\end{array}$ & $P$-value \\
\hline Perfluorocarbon liquid use & $47(78)$ & $16(80)$ & 0.88 \\
\hline Lensectomy & $4 / 14(29)$ & $5 / 47(I I)$ & 0.10 \\
\hline Not reattached at last follow-up & $2(3.3)$ & $2(10)$ & 0.24 \\
\hline Operation for recurrent retinal detachment & $7(12)$ & $4(20)$ & 0.35 \\
\hline Preoperative VA ( $\geq 20 / 400)$ & $32(53)$ & II (55) & 0.90 \\
\hline Final VA $(\geq 20 / 400)$ & $43(72)$ & $12(60)$ & 0.34 \\
\hline
\end{tabular}

Abbreviations: GRT, giant retinal tear; VA, visual acuity. 

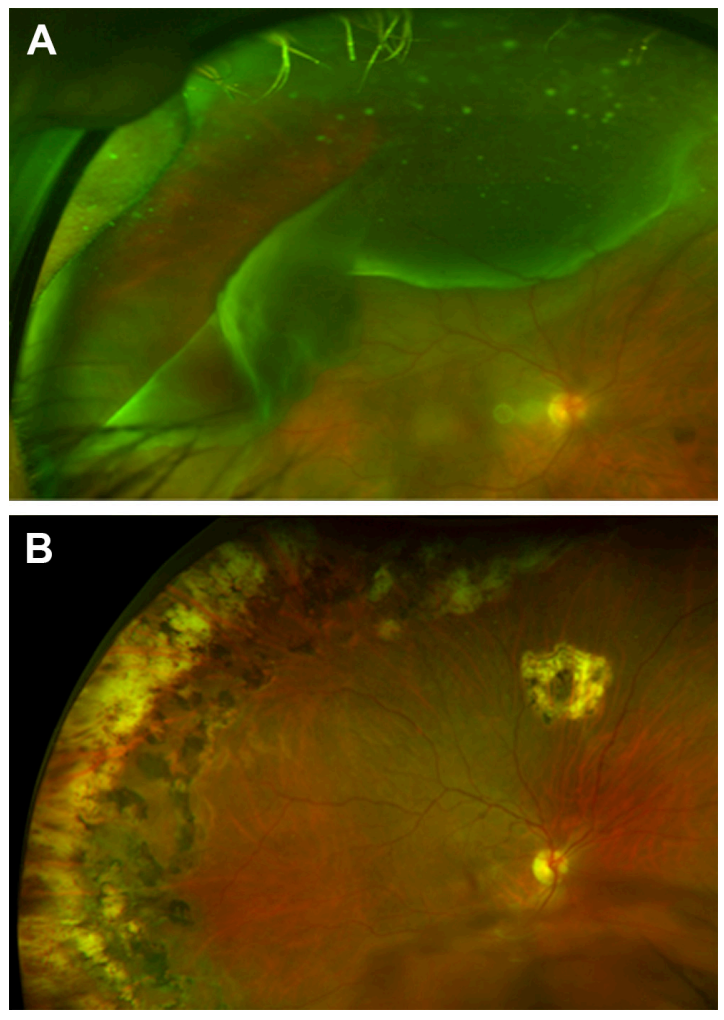

Figure I Case example I: a 49-year-old man who presented with a macula sparing superotemporal 3 clock hour giant retinal tear-associated retinal detachment of the right eye (A). He underwent a 23-gauge pars plana vitrectomy, endolaser, fluid-air exchange, and silicone oil tamponade; the silicone oil was subsequently removed 5 months later and the retina remained attached after 2 years (B).

the previous series. In the current series, fewer lensectomies were performed in phakic eyes $(9 / 61$ eyes, $15 \%)$ at the time of initial surgery compared with the earlier series (23/56 eyes, $41 \% ; P=0.001)$.

\section{Discussion}

The management of GRT-associated RDs has been substantially more successful with modern surgical techniques.
In addition to favorable anatomic outcomes, postoperative BCVA in this study has demonstrated improvement compared with previous series. ${ }^{8,9}$ The visual success of eyes in this study was encouraging, given that the majority $(65 \%)$ already had macular detachment. Although another study found gas tamponade associated with better final BCVA in fovea-sparing RDs compared with silicone oil, the current series did not identify any difference in final BCVA between the two groups. ${ }^{10}$

Surgical outcomes for RDs associated with GRTs have improved during the past 20 years. ${ }^{3,7-9,11}$ The historic reattachment rate has been as low as $11 \%$, whereas the rates of single surgery reattachment $(86 \%)$ and final reattachment (95\%) rates in the current study are comparable with recently published studies and reflect the value of the vitreoretinal tools now available. ${ }^{3,6-9,11,12}$ Perfluorocarbon liquids seem to have offered the most benefit in this improvement, but outcomes have also improved concurrent with the inception of wide-field viewing systems, high-speed cutters, and small gauge vitrectomy.

There are still a variety of surgical technique variations advocated, but there is virtual unanimity that PPV and perfluorocarbon liquids are preferred management components. ${ }^{13}$ The current study documents perfluorocarbon liquid use in $78 \%$ of cases, regardless of GRT extent, contrasting with the earlier study using it more frequently in larger GRTs (statistical significance not reported). ${ }^{7}$ This current series also found that reoperations did not differ regardless of GRT size. Although the extent of the GRT may impact the technical difficulty of the surgery, it did not seem to determine surgical management or anatomic success.

Silicone oil was most commonly used for internal tamponade and had a high anatomic success rate similar to that of $\mathrm{C}_{3} \mathrm{~F}_{8}$, consistent with previous studies. ${ }^{11,14,15}$ In one

Table 4 Surgical management of giant retinal tear-associated retinal detachments and anatomic outcomes over 13 years

\begin{tabular}{|c|c|c|c|}
\hline $\begin{array}{l}\text { Intraoperative/postoperative } \\
\text { parameters }\end{array}$ & $\begin{array}{l}2005-2010^{a} \\
N=79(\%)\end{array}$ & $\begin{array}{l}20 I I-2017 \\
N=80(\%)\end{array}$ & $\begin{array}{l}\text { 2005-2017 combined } \\
N=159(\%)\end{array}$ \\
\hline Scleral buckle/pars plana vitrectomy & $67 / 79(85)$ & $6 I / 80(76)$ & $128 / 159(81)$ \\
\hline Perfluorocarbon liquid use & $56 / 79(7 I)$ & $60 / 80(75)$ & II6/159 (73) \\
\hline Lensectomy (in phakic eyes) $^{\mathrm{b}}$ & $23 / 56(4 I)$ & $9 / 61(15)$ & $32 / 117(27)$ \\
\hline Silicone oilc & $45 / 79(57)$ & $54 / 80(68)$ & $99 / 159(62)$ \\
\hline Recurrent retinal detachment & $14 / 79(18)$ & $11 / 80(14)$ & $25 / 159(16)$ \\
\hline Final reattachment & $73 / 79(92)$ & $76 / 80(95)$ & 149/I59 (94) \\
\hline$V A \geq 20 / 40$ & $17 / 79(22)$ & $15 / 80(19)$ & $32 / 159(20)$ \\
\hline$V A \geq 20 / 400$ & $58 / 79(73)$ & $54 / 80(68)$ & $112 / 159(70)$ \\
\hline
\end{tabular}

Notes: ${ }^{2}$ Data from Gonzalez et al. ${ }^{7}$ 'Lensectomy used during the initial surgical procedure. 'Silicone oil used during the initial surgical procedure. Abbreviation: VA, visual acuity. 
report with the predominant use of silicone oil rather than gas, the superiority of silicone oil tamponade could not be confirmed. ${ }^{16}$ While it is uncommon to use $\mathrm{SF}_{6}$, and this was used in a tiny subset in the current study, this study was consistent with other studies that have associated $\mathrm{SF}_{6}$ with a lower success rate. ${ }^{11,14}$

Scleral buckling in GRT surgery has been controversial, as there is a general tendency away from SB use in current $\mathrm{RD}$ repair approaches. Scleral indentation from a buckle can distort the shape of the globe and might potentially increase the risk of GRT slippage. ${ }^{17}$ On the contrary, an encircling buckle may provide vitreous base support and, particularly in the case of anterior PVR, may reduce the risk of redetachment by preemptively neutralizing subsequent traction..$^{3,8}$ Given that there was a higher proportion of phakic eyes that received an $\mathrm{SB}$, it is possible that the indentation from the buckle would allow for easier shaving of the vitreous base in phakic eyes. The high rate of SB usage in the current study was similar to that of many other studies and might reflect a bias of the investigators. ${ }^{7,18}$ Goezinne et al compared the addition of SB procedure with PPV in patients undergoing retinal reattachment surgery for GRTs and found that the presence of an encircling SB was a positive predictive factor for retinal reattachment. ${ }^{19}$ In contrast, other retrospective studies (as well as the current study) found that the rate of redetachment was similar in the cases of PPV alone compared with a combined PPV/SB approach. ${ }^{711}$ In a 2018 reported series regarding the use of 25-gauge vitrectomy for GRT, neither the extent of GRT nor the use of scleral buckling influenced anatomic or visual outcomes. ${ }^{16}$

The rationale for lensectomy is to allow access for more effective vitreous base shaving, especially since progressive postoperative nuclear sclerosis with the vitrectomy is inevitable. In the earlier study from the same institution, $41 \%$ of phakic patients underwent pars plana lensectomy with initial reattachment surgery, while only $15 \%$ of phakic patients in the current series did so (Table 4). ${ }^{7}$ While it has been reported that GRT eyes without PVR usually achieve surgical success without undergoing lensectomies, it is possible that the presence of PVR would make lensectomies more likely. ${ }^{20}$ Larger GRTs were not more likely to be managed with lensectomies in this series, and while other studies have not compared rate of lensectomy with GRT size, the decision to perform lensectomy is multifactorial and subject to the surgeon's bias.

The limitations of this study include its retrospective nature, nonstandard management protocol among several surgeons, and variable follow-up. The individual surgeon determined the approach, and therefore, it is difficult to draw definitive conclusions on techniques. In spite of these limitations, the current study represents a contemporary surgical case series of patients with GRTs.

\section{Conclusion}

GRTs are still managed with variable surgical techniques even within the same practice. No techniques have been established objectively, but there is a consensus on the use of perfluorocarbon liquids, while many other maneuvers are clinical impressions gleaned from individual surgeons' experiences. The current series affirms the high success rates that accompany a high prevalence of initial PPV, perfluorocarbon liquids use, common combined PPV/SB, and either silicone oil or $\mathrm{C}_{3} \mathrm{~F}_{8}$ that seem to have yielded reasonable results consistent with contemporary reports and experience. ${ }^{7,11,21}$

\section{Acknowledgment}

Supported in part by the NIH core grant and an unrestricted grant from Research to Prevent Blindness, New York, NY.

\section{Disclosure}

The authors report no conflicts of interest in this work.

\section{References}

1. Ang GS, Townend J, Lois N. Epidemiology of giant retinal tears in the United Kingdom: the British Giant Retinal Tear Epidemiology Eye Study (BGEES). Invest Ophthalmol Vis Sci. 2010;51(9):4781-4787.

2. Aylward GW, Cooling RJ, Leaver PK. Trauma-induced retinal detachment associated with giant retinal tears. Retina. 1993;13(2):136-141.

3. Lee SY, Ong SG, Wong DW, Ang CL. Giant retinal tear management: an Asian experience. Eye (Lond). 2009;23(3):601-605.

4. Peyman GA, Rednam KR, Seetner AA. Retinal microincarceration with penetrating diathermy in the management of giant retinal tears. Arch Ophthalmol. 1984;102(4):562-565.

5. Norton EW, Aaberg T, Fung W, Curtin VT. Giant retinal tears. I. Clinical management with intravitreal air. Am J Ophthalmol. 1969;68(6): 1011-1021.

6. Chang S, Lincoff H, Zimmerman NJ, Fuchs W. Giant retinal tears. Surgical techniques and results using perfluorocarbon liquids. Arch Ophthalmol. 1989;107(5):761-766.

7. Gonzalez MA, Flynn HW, Smiddy WE, Albini TA, Tenzel P. Surgery for retinal detachment in patients with giant retinal tear: etiologies, management strategies, and outcomes. Ophthalmic Surg Lasers Imaging Retina. 2013;44(3):232-237.

8. Kertes PJ, Wafapoor H, Peyman GA, Calixto N Jr, Thompson H. The management of giant retinal tears using perfluoroperhydrophenanthrene. A multicenter case series. Vitreon Collaborative Study Group. Ophthalmology. 1997;104(7):1159-1165.

9. Scott IU, Murray TG, Flynn HW Jr, Feuer WJ, Schiffman JC; Perfluoron Study Group. Outcomes and complications associated with giant retinal tear management using perfluoro-n-octane. Ophthalmology. 2002;109(10):1828-1833.

10. Banerjee PJ, Chandra A, Petrou P, Charteris DG. Silicone oil versus gas tamponade for giant retinal tear-associated fovea-sparing retinal detachment: a comparison of outcome. Eye (Lond). 2017;31(9):1302-1307.

11. Pitcher JD 3rd, Khan MA, Storey PP, et al. Contemporary management of rhegmatogenous retinal detachment due to giant retinal tears: a consecutive case series. Ophthalmic Surg Lasers Imaging Retina. 2015;46(5):566-570. 
12. Kanski JJ. Giant retinal tears. Am J Ophthalmol. 1975;79(5):846-852.

13. Al-Khairi AM, Al-Kahtani E, Kangave D, Abu El-Asrar AM. Prognostic factors associated with outcomes after giant retinal tear management using perfluorocarbon liquids. Eur J Ophthalmol. 2008;18(2): 270-277.

14. Vitrectomy with silicone oil or sulfur hexafluoride gas in eyes with severe proliferative vitreoretinopathy: results of a randomized clinical trial. Silicone Study Report 1. Arch Ophthalmol. 1992;110(6):770-779.

15. Batman $\mathrm{C}$, Cekiç O. Vitrectomy with silicone oil or long-acting gas in eyes with giant retinal tears: long-term follow-up of a randomized clinical trial. Retina. 1999;19(3):188-192.

16. Kumar V, Kumawat D, Bhari A, Chandra P. Twenty-five-gauge pars plana vitrectomy in complex retinal detachments associated with giant retinal tear. Retina. 2018;38(4):670-677.

17. Kreiger AE, Lewis $H$. Management of giant retinal tears without scleral buckling. Use of radical dissection of the vitreous base and perfluoro-octane and intraocular tamponade. Ophthalmology. 1992; 99(4):491-497.
18. Gonzalez MA, Flynn HW Jr, Smiddy WE, Albini TA, Berrocal AM, Tenzel P. Giant retinal tears after prior pars plana vitrectomy: management strategies and outcomes. Clin Ophthalmol. 2013;7:1687-1691.

19. Goezinne F, LA Heij EC, Berendschot TT, et al. Low redetachment rate due to encircling scleral buckle in giant retinal tears treated with vitrectomy and silicone oil. Retina. 2008;28(3):485-492.

20. Verstraeten T, Williams GA, Chang S, et al. Lens-sparing vitrectomy with perfluorocarbon liquid for the primary treatment of giant retinal tears. Ophthalmology. 1995;102(1):17-20.

21. Jain N, Kozak JA, Niziol LM, Musch DC, Zacks DN. Vitrectomy alone in the management of giant retinal tears. Ophthalmic Surg Lasers Imaging Retina. 2014;45(5):421-427.
Clinical Ophthalmology

\section{Publish your work in this journal}

Clinical Ophthalmology is an international, peer-reviewed journal covering all subspecialties within ophthalmology. Key topics include: Optometry; Visual science; Pharmacology and drug therapy in eye diseases; Basic Sciences; Primary and Secondary eye care; Patient Safety and Quality of Care Improvements. This journal is indexed on

\section{Dovepress}

PubMed Central and CAS, and is the official journal of The Society of Clinical Ophthalmology (SCO). The manuscript management system is completely online and includes a very quick and fair peer-review system, which is all easy to use. Visit http://www.dovepress.com/ testimonials.php to read real quotes from published authors. 